\title{
Somatostatin Receptor Antagonists for Imaging and Therapy
}

\author{
Melpomeni Fani ${ }^{1,2}$, Guillaume P. Nicolas ${ }^{1,3}$, and Damian Wild ${ }^{1,3}$ \\ ${ }^{1}$ Division of Nuclear Medicine, University Hospital Basel, Basel, Switzerland; ${ }^{2}$ Division of Radiopharmaceutical Chemistry, \\ University Hospital Basel, Basel, Switzerland; and ${ }^{3}$ Center for Neuroendocrine and Endocrine Tumors, University Hospital Basel, \\ Basel, Switzerland
}

Somatostatin receptor (sstr) scintigraphy for imaging and sstr analogs for treatment have been used for more than $20 \mathrm{y}$. An important improvement in recent years was the introduction of peptide receptor radionuclide therapy with radiolabeled sstr agonists, such as $\left[{ }^{90} \mathrm{Y}-\mathrm{DOTA}^{0}, \mathrm{Tyr}^{3}\right]$ octreotide or $\left[{ }^{177} \mathrm{Lu}^{-D O T A}{ }^{0}, \mathrm{Tyr}^{3}\right]$ octreotide $\left({ }^{90} \mathrm{Y}\right.$ - or ${ }^{177} \mathrm{Lu}-\mathrm{DOTATOC}$, respectively) and $\left[{ }^{177} \mathrm{Lu}-\right.$ DOTA $^{0}$, Tyr $^{3}$ ]octreotate ( ${ }^{177}$ Lu-DOTATATE). PET/CT with ${ }^{68} \mathrm{Ga}$-labeled sstr agonists, such as ${ }^{68} \mathrm{Ga}-D O T A T O C,{ }^{68} \mathrm{Ga}$-DOTATATE, and $\left[{ }^{68} \mathrm{Ga}-\mathrm{DOTA}, 1-\mathrm{Nal}{ }^{3}\right]$ octreotide $\left({ }^{68} \mathrm{Ga}-\mathrm{DOTANOC}\right)$, plays an important role in staging and restaging neuroendocrine tumors. Most importantly, sstr scintigraphy and sstr PET/CT can distinguish patients who will qualify for and benefit from peptide receptor radionuclide therapy. This characteristic of sstr targeting is important because it allows a personalized treatment approach (theranostic approach). Until recently, it was thought that internalization of the radiolabeled agonist was mandatory for sstr-mediated imaging and therapy. It was Ginj et al. who proposed in 2006 the paradigm shift that radiolabeled sstr antagonists may perform better than agonists despite the lack of internalization. Despite the rather limited number of head-to-head comparisons of sstr antagonists and agonists, the superiority of sstr antagonists was demonstrated in several cases. From a small library of sstr antagonists, the analog JR11 (СpaC[D-Cys-Aph(Hor)-D-Aph(Cbm)-Lys-Thr-Cys]-D-Tyr-NH ${ }_{2}$ ), an antagonist with selectivity for sstr subtype 2 , showed the best overall characteristics for sstr subtype 2 targeting and was therefore selected for clinical translation. JR11 is under clinical development as a PET imaging agent when labeled with ${ }^{68} \mathrm{Ga}\left({ }^{68} \mathrm{Ga}-\mathrm{NODAGA}-J R 11\right.$ or ${ }^{68} \mathrm{Ga}$-OPS202) and as a therapeutic agent when labeled with ${ }^{177}$ Lu ( ${ }^{177}$ Lu-DOTA-JR11 or ${ }^{177}$ Lu-OPS201). In this article, we discuss the development and current status of radiolabeled sstr antagonists. Evidence based on preclinical work, on quantitative in vivo autoradiography of human tumor slices, and on human data now supports a shift to sstr antagonists.

Key Words: neuroendocrine tumors; somatostatin receptor antagonists; peptide receptor radionuclide therapy; somatostatin receptor $\mathrm{PET} / \mathrm{CT}$

J Nucl Med 2017; 58:61S-66S

DOI: 10.2967/jnumed.116.186783

\section{$\mathbf{S}$} are highly attractive targets for imaging and treatment of patients

Received Apr. 7, 2017; revision accepted Apr. 26, 2017.

For correspondence or reprints contact: Damian Wild, Division of Nuclear Medicine, University Hospital Basel, Petersgraben 4, 4031 Basel, Switzerland.

E-mail: damian.wild@usb.ch

COPYRIGHT (C 2017 by the Society of Nuclear Medicine and Molecular Imaging. with neuroendocrine tumors (NETs) and neuroendocrine neoplasias, respectively. For example, sstr scintigraphy for imaging and sstr analogs (SSA) for treatment have been used for more than $20 \mathrm{y}$. Important improvements in recent years were the introduction of peptide receptor radionuclide therapy (PRRT) with radiolabeled sstr agonists, such as ${ }^{90} \mathrm{Y}$ - or ${ }^{177} \mathrm{Lu}-\mathrm{DOTATOC}$ and ${ }^{177} \mathrm{Lu}-$ DOTATATE, and the introduction of sstr PET/CT with (mainly) ${ }^{68} \mathrm{Ga}$-labeled sstr agonists, such as DOTATOC, DOTATATE, and DOTANOC (1). sstr PET/CT currently plays an important role in detection of the primary tumor, detection of an unknown primary tumor, staging, restaging, and assessment of the treatment response in patients with NETs (2). Furthermore-and most importantly - sstr scintigraphy and sstr PET/CT can distinguish patients who will qualify for and benefit from PRRT and treatment with SSA. This characteristic of sstr targeting is important because it allows a personalized treatment approach (theranostic approach).

NETTER-1 was the first large, randomized, controlled phase 3 trial evaluating ${ }^{177} \mathrm{Lu}$-DOTATATE for PRRT in patients with midgut NETs. Progression-free survival rates at month 20 were $65.2 \%$ in the ${ }^{177} \mathrm{Lu}$-DOTATATE group and $10.8 \%$ in the control group (high-dose SSA) (3). An interim analysis showed that PRRT has a tendency for longer overall survival than SSA. The results of this trial, first published in an abstract in 2015 (4), already had an impact on the current treatment recommendation and algorithm. PRRT is now recommended by the European Neuroendocrine Tumor Society as second-line treatment after progression under treatment with SSA in patients with metastatic grade 1 or 2 midgut NETs (5). This development indicates that sstr targeting with radiolabeled tracers is relevant not only for imaging but also for treatment of patients with NETs.

An important development in the field of sstr targeting was the recent introduction of sstr antagonists, which seemed to recognize more binding sites on receptors and which showed favorable pharmacokinetics and better tumor visualization than agonists, despite very poor internalization rates $(6,7)$. Current preclinical and clinical evaluations of radiolabeled sstr antagonists for imaging and therapy and their clinical potential, not only in NETs but also in other tumors, are discussed here.

\section{PRECLINICAL DEVELOPMENT OF RADIOLABELED SSTR ANTAGONISTS}

In 1996, Bass et al. found that the inversion of chirality at positions 1 and 2 of the octapeptide (octreotide family) converted an agonist into a potent antagonist (8). Soon after, structureactivity relationship studies by Hocart et al. revealed different potent antagonists (9). These antagonists were used as lead structures by Jean Rivier (Salk Institute for Biologic Studies, La Jolla, CA), Jean Claude Reubi (University of Bern, Bern, Switzerland), and 
Helmut R. Mäcke (University Hospital of Basel, Basel, Switzerland) in collaboration for the development of new sstr antagonists, including DOTA conjugates, for labeling with radiometals $(6,10)$.

\section{First Generation of Radiolabeled sstr Antagonists}

The first radiolabeled sstr antagonists were based on the sstr2selective analog sst2-ANT or BASS (Table 1), developed by Bass et al. (8), and the sstr3-selective antagonist sst3-ODN-8, developed by Reubi et al. (11). Both antagonists were labeled with ${ }^{111}$ In via the chelator DOTA and were evaluated in vivo using human embryonic kidney (HEK) cell line 293 stably transfected with sstr2. A direct comparison of ${ }^{111}$ In-DOTA-BASS (50\% inhibitory concentration $\left[\mathrm{IC}_{50}\right], 9.4 \pm 0.4 \mathrm{nM}[$ mean \pm SEM] (6)) and highaffinity ${ }^{111}$ In-diethylenetriaminepentaacetic acid (DTPA)-TATE

TABLE 1

Somatostatin Analog Affinities

\begin{tabular}{|c|c|c|c|c|c|c|c|}
\hline \multirow[b]{2}{*}{ Somatostatin analog } & \multirow[b]{2}{*}{ Chemical structure } & \multicolumn{5}{|c|}{ Affinity } & \multirow[b]{2}{*}{ Status } \\
\hline & & sstr1 & sstr2 & sstr3 & sstr4 & sstr5 & \\
\hline \multicolumn{8}{|l|}{ Agonist } \\
\hline In-DTPA-octreotide* & $\begin{array}{l}{ }^{111} \text { In-DTPA-D-Phe-cyclo } \\
\text { (Cys-Phe-D-Trp-Lys-Thr-Cys) } \\
\text { Thr(ol) }\end{array}$ & $>10,000$ & $22 \pm 3.6$ & $182 \pm 13$ & $>1,000$ & $237 \pm 52$ & $\begin{array}{l}\text { FDA } \\
\text { approved }\end{array}$ \\
\hline Ga-DOTATOC* & $\begin{array}{l}{ }^{68} \text { Ga-DOTA-D-Phe-cyclo } \\
\text { (Cys-Tyr-D-Trp-Lys-Thr-Cys) } \\
\text { Thr(ol) }\end{array}$ & $>10,000$ & $2.5 \pm 0.5$ & $613 \pm 140$ & $>1,000$ & $73 \pm 21$ & $\begin{array}{l}\text { Phase } 2 \\
\text { studies }\end{array}$ \\
\hline Y-DOTATOC* & $\begin{array}{l}\text { 90Y-DOTA-D-Phe-cyclo } \\
\text { (Cys-Tyr-D-Trp-Lys-Thr-Cys) } \\
\text { Thr(ol) }\end{array}$ & $>10,000$ & $11 \pm 1.7$ & $389 \pm 135$ & $>10,000$ & $114 \pm 29$ & $\begin{array}{l}\text { Phase } 2 \\
\text { studies }\end{array}$ \\
\hline Ga-DOTATATE* & $\begin{array}{l}{ }^{68} \mathrm{Ga}-\mathrm{DOTA}-\mathrm{D}-\mathrm{Phe}-\mathrm{cyclo} \\
\text { (Cys-Tyr-D-Trp-Lys-Thr-Cys)Thr }\end{array}$ & $>10,000$ & $0.20 \pm 0.04$ & $>1,000$ & $300 \pm 140$ & $377 \pm 18$ & $\begin{array}{l}\text { FDA } \\
\text { approved }\end{array}$ \\
\hline Y-DOTATATE* & $\begin{array}{l}\text { 90Y-DOTA-D-Phe-cyclo } \\
\text { (Cys-Tyr-D-Trp-Lys-Thr-Cys)Thr }\end{array}$ & $>10,000$ & $1.6 \pm 0.4$ & $>1,000$ & $523 \pm 239$ & $187 \pm 50$ & Unknown \\
\hline Lu-DOTATATE† ${ }^{\dagger}$ & $\begin{array}{l}\text { 177 Lu-DOTA-D-Phe-cyclo } \\
\text { (Cys-Tyr-D-Trp-Lys-Thr-Cys)Thr }\end{array}$ & $>1,000$ & $2.0 \pm 0.8$ & $162 \pm 16$ & $>1,000$ & $>1,000$ & $\begin{array}{c}\text { Phase } 3 \\
\text { study }\end{array}$ \\
\hline Ga-DOTANOC $\ddagger$ & $\begin{array}{l}{ }^{68} \text { Ga-DOTA-D-Phe-cyclo } \\
\text { (Cys-1-Nal-D-Trp-Lys-Thr-Cys) } \\
\text { Thr(ol) }\end{array}$ & $>10,000$ & $1.9 \pm 0.4$ & $40.0 \pm 5.8$ & $260 \pm 74$ & $7.2 \pm 1.6$ & $\begin{array}{l}\text { Phase } 2 \\
\text { studies }\end{array}$ \\
\hline \multicolumn{8}{|l|}{ Antagonist } \\
\hline In-DOTA-BASS ${ }^{\S}$ & $\begin{array}{l}{ }^{111} \text { In-DOTA-p-NO } \mathrm{N}_{2} \text {-Phe-cyclo } \\
\text { (D-Cys-Tyr-D-Trp-Lys-Thr-Cys) } \\
\text { D-Tyr-NH } 2\end{array}$ & $>1,000$ & $9.4 \pm 0.4$ & $>1,000$ & $380 \pm 57$ & $>1,000$ & Pilot study \\
\hline In-DOTA-JR11|| & $\begin{array}{l}{ }^{111} \text { In-DOTA-Cpa-cyclo[D-Cys-Aph } \\
\text { (Hor)-D-Aph } \\
\text { (Cbm)-Lys-Thr-Cys]-D-Tyr-NH } 2\end{array}$ & $>1,000$ & $3.8 \pm 0.7$ & $>1,000$ & $>1,000$ & $>1,000$ & Pilot study \\
\hline $\begin{array}{l}\text { Ga-DOTA-JR11\| } \\
\text { (Ga-OPS201) }\end{array}$ & $\begin{array}{l}{ }^{68} \text { Ga-DOTA-Cpa-cyclo[D-Cys-Aph } \\
\text { (Hor)-D-Aph } \\
\text { (Cbm)-Lys-Thr-Cys]-D-Tyr-NH }{ }_{2}\end{array}$ & $>1,000$ & $29 \pm 2.7$ & $>1,000$ & $>1,000$ & $>1,000$ & Pilot study \\
\hline $\begin{array}{l}\text { Ga-NODAGA-JR11॥ } \\
\text { (Ga-OPS202) }\end{array}$ & $\begin{array}{l}{ }^{68} \text { Ga-NODAGA-Cpa-cyclo[D-Cys- } \\
\text { Aph(Hor)-D-Aph(Cbm)-Lys-Thr- } \\
\text { Cys]-D-Tyr-NH2 }\end{array}$ & $>1,000$ & $1.2 \pm 0.2$ & $>1,000$ & $>1,000$ & $>1,000$ & $\begin{array}{c}\text { Phase } 1 / 2 \\
\text { study }\end{array}$ \\
\hline $\begin{array}{l}\text { Lu-DOTA-JR11"I } \\
\text { (Lu-OPS201) }\end{array}$ & $\begin{array}{l}{ }^{177} \text { Lu-DOTA-Cpa-cyclo[D-Cys-Aph } \\
\text { (Hor)-D-Aph } \\
\text { (Cbm)-Lys-Thr-Cys]-D-Tyr-NH }{ }_{2}\end{array}$ & $>1,000$ & $0.73 \pm 0.15$ & $>1,000$ & $>1,000$ & $>1,000$ & Pilot study \\
\hline
\end{tabular}

${ }^{*}$ Data are from Reubi et al. (12).

${ }^{\dagger}$ Data are from Schottelius et al. (23) (different laboratory).

${ }^{\ddagger}$ Data are from Antunes et al. (24).

${ }^{\S}$ Data are from Ginj et al. (6).

"Data are from Fani et al. (15).

FDA = Food and Drug Administration; 1-Nal = 1-naphthylalanine; Cpa = 4-Cl-phenylalanine; Aph(Hor) = 4-amino-L-hydroorotylphenylalanine; $\mathrm{D}-\mathrm{Aph}(\mathrm{Cbm})=\mathrm{D}-4$-aminocarbamoylphenylalanine.

All data are mean \pm SD, excepting Lu-DOTATATE data, which are mean \pm SD (laboratory that generated Lu-DOTATATE data was different from laboratory that generated rest of data). 
$\left(\mathrm{IC}_{50}, 1.3 \pm 0.2 \mathrm{nM}(12)\right)$ revealed that tumor uptake for the radiolabeled sstr2 antagonist was 2-fold higher, despite its lower affinity. The same was true for ${ }^{111}$ In-DOTA-sst3-ODN-8 in a comparison with ${ }^{111}$ In-DOTANOC in HEK-sstr3 xenografts. Also surprising was the long-lasting tumor uptake of ${ }^{111}$ In-DOTA-BASS and ${ }^{177} \mathrm{Lu}$-DOTA-BASS, considering the lack of internalization (13). Conversely, the sstr2 antagonist BASS labeled with ${ }^{64} \mathrm{Cu}$ via the chelator 4,11-bis(carboxymethyl)-1,4,8,11-tetraazabicyclo [6.6.2] hexadecane (CB-TE2A) $\left({ }^{64} \mathrm{Cu}-\mathrm{CB}-\mathrm{TE} 2 \mathrm{~A}-\mathrm{BASS}\right) \mathrm{did}$ not show higher tumor uptake than the agonist ${ }^{64} \mathrm{Cu}-\mathrm{CB}-\mathrm{TE} 2 \mathrm{~A}-$ octreotate in sstr2-positive AR42J xenografts (14). However, in all studies, radiolabeled sstr antagonists recognized a larger number of binding sites in vitro than did agonists $(6,14)$.

\section{Second Generation of Radiolabeled sstr Antagonists}

The initial indications that antagonists may be superior to agonists led to the design of more potent sstr2 antagonists with improved affinity (10); several were studied as radiotracers $(15,16)$.

On the basis of the new sstr2 antagonist LM3 ( $p$-Cl-Phe-cyclo (D-Cys-Tyr-D-Aph(Cbm)-Lys-Thr-Cys)D-Tyr- $\mathrm{NH}_{2}$ ), various PET imaging agents were developed using 3 different macrocyclic chelating systems (DOTA, NODAGA, and CB-TE2A) and 2 PET radiometals $\left({ }^{68} \mathrm{Ga}\right.$ and $\left.{ }^{64} \mathrm{Cu}\right)(16)$. This study clearly demonstrated that the chelate makes a difference in the affinity and pharmacokinetics of the radiolabeled sstr2 antagonists. For instance, the sstr2 affinity of ${ }^{68} \mathrm{Ga}$-NODAGA-LM3 was 10 -fold higher than that of ${ }^{68} \mathrm{Ga}$-DOTA-LM3, whereas ${ }^{64} \mathrm{Cu}$-CB-TE2A-LM3 showed almost no washout from the tumor up to $24 \mathrm{~h}$ after injection (unexpected for a noninternalized radioligand)—not the case with ${ }^{64} \mathrm{Cu}-\mathrm{NODAGA}-\mathrm{LM} 3$. These findings may be important if therapy with the $\beta^{-}$-emitter ${ }^{67} \mathrm{Cu}$ (half-life, $62 \mathrm{~h}$ ) is being considered. However, the ratios of tumor to normal tissue were remarkably higher for ${ }^{64} \mathrm{Cu}-\mathrm{NODAGA}-\mathrm{LM} 3$; this parameter is important for good image contrast.

A more comprehensive study involving the evaluation of 3 different sstr2 antagonists-LM3, JR10 ( $p$ - $\mathrm{NO}_{2}$-Phe-c[D-Cys-TyrD-Aph(Cbm)-Lys-Thr-Cys]-D-Tyr-NH ${ }_{2}$, and JR11 (Cpa-c[D-CysAph(Hor)-D-Aph(Cbm)-Lys-Thr-Cys]-D-Tyr- $\mathrm{NH}_{2}$ ) - in combination with 2 chelators (DOTA and NODAGA) and various (radio) metals-including In(III), Y(III), Lu(III), Cu(II), and $\mathrm{Ga}(\mathrm{III})$ clearly demonstrated the extremely high sensitivity of the antagonists to modifications such as complexation with distinct radiometals or substitution of a chelator by another (15). The gallium-labeled DOTA analogs had lower affinity for sstr2 than the respective Y(III)-DOTA, Lu(III)-DOTA, or In(III)-DOTA counterparts. Interestingly, however, substitution of DOTA by the NODAGA chelator was able to substantially increase the binding affinity of the Ga(III)-NODAGA analogs, compared with the Ga(III)-DOTA analogs. That study illustrated the great potential of the antagonists, because even a low-affinity antagonist was shown to be slightly superior to a high-affinity agonist, outweighing the affinity differences. More specifically, ${ }^{68} \mathrm{Ga}$-DOTA-JR11, having a dramatically lower affinity for sstr2 ( 150-fold) than ${ }^{68}$ Ga-DOTATATE (Table 1), showed a tumor uptake that was 1.3-fold higher, and ${ }^{68} \mathrm{Ga}$-NODAGA-JR11, having a 6-fold lower affinity than ${ }^{68} \mathrm{Ga}-$ DOTATATE (Table 1), showed a tumor uptake that was up to 1.7fold higher (15).

Of the radiolabeled sstr2 antagonists mentioned so far, the analog JR11 performed the best in preclinical settings. JR11 was selected for clinical development as a PET imaging agent labeled with ${ }^{68} \mathrm{Ga}$ using the chelator NODAGA $\left({ }^{68} \mathrm{Ga}-\mathrm{NODAGA}-J R 11\right.$ or $\left.{ }^{68} \mathrm{Ga}-\mathrm{OPS} 202\right)$ and as a therapeutic agent labeled with ${ }^{177} \mathrm{Lu}$ using the chelator DOTA $\left({ }^{177} \mathrm{Lu}-\mathrm{DOTA}-J R 11\right.$ or $\left.{ }^{177} \mathrm{Lu}-\mathrm{OPS} 201\right)$.

\section{Preclinical Evaluation of Radiolabeled sstr Antagonists for Treatment}

Three preclinical studies investigating different aspects of the use of radiolabeled antagonists for PRRT have been published. These studies focused on the new therapeutic agent ${ }^{177} \mathrm{Lu}$-DOTAJR11 ( $\left.{ }^{177} \mathrm{Lu}-\mathrm{OPS} 201\right)$ and explored its biodistribution, pharmacokinetics, dosimetry, and therapeutic effect. The studies were performed in 3 different animal models: 2 tumor-bearing murine models for a comparison to the established agonist ${ }^{177} \mathrm{Lu}$-DOTATATE $(17,18)$ and 1 tumor-free porcine model for dosimetry purposes $(19)$.

A head-to-head comparison of ${ }^{177} \mathrm{Lu}$-DOTA-JR11 and ${ }^{177} \mathrm{Lu}-$ DOTATATE was performed with HEK-hsstr2 (human sstr2) xenografts (18). After administration of $10 \mathrm{pmol}$ of peptide, ${ }^{177} \mathrm{Lu}-$ DOTA-JR11 showed significantly higher tumor uptake $(23.9 \pm 4.5$ percentage injected activity per gram) than ${ }^{177}$ Lu-DOTATATE (17.8 \pm 4.4 percentage injected activity per gram) at $4 \mathrm{~h}$ after injection. Most importantly, this increase persisted over time, resulting in a tumor radiation dose that was 2.6 times higher for the radiolabeled sstr2 antagonist than for the agonist (18). The results of the mass escalation study were impressive, showing that optimization of the administered peptide amount enabled substantial suppression of the background activity, whereas tumor uptake was not significantly affected (Fig. 1). Consequently, increasing the administered amount of ${ }^{177}$ Lu-DOTA-JR11 to a certain extent (from 10 to $200 \mathrm{pmol}$ ) may improve the safety profile of PRRT and reduce potentially hematologic toxicity (18).

Using H69 xenografts, Dalm et al. reported tumor uptake that was 5 times higher for ${ }^{177}$ Lu-DOTA-JR 11 than for ${ }^{177}$ Lu-DOTATATE at $4 \mathrm{~h}$ after injection and a tumor radiation dose that was 4.4 times higher after the administration of approximately $300 \mathrm{pmol}$ of each radiotracer (17). In an in vivo therapy study, compared with ${ }^{177} \mathrm{Lu}-$ DOTATATE, ${ }^{177} \mathrm{Lu}$-DOTA-JR11 resulted in a higher median survival rate (71 vs. $61 \mathrm{~d})$ and in a longer delay (1.4 times) in tumor growth $(26 \pm 7$ vs. $18 \pm 5$ d). Despite the fact that $88 \% \pm 1 \%$ of

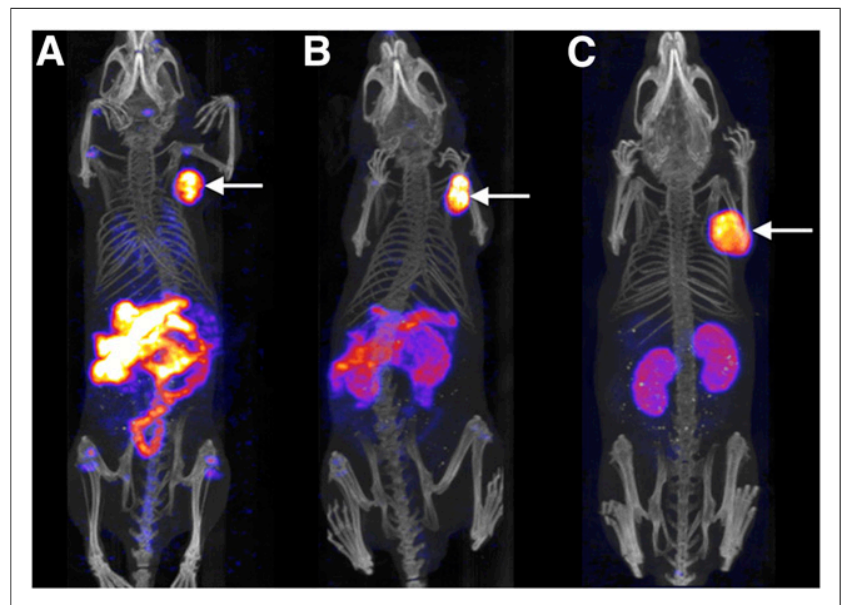

FIGURE 1. Nano-SPECT/CT maximum-intensity-projection images of HEK-hsstr2 xenografts $4 \mathrm{~h}$ after administration of $20 \mathrm{pmol}(\mathrm{A}), 200 \mathrm{pmol}$ (B), and 2,000 pmol (C) of ${ }^{177}$ Lu-DOTA-JR11 ( ${ }^{177}$ Lu-OPS201). Increase in peptide amount significantly decreased background activity, whereas tumor uptake (arrows) was not significantly affected. (Adapted from (18).) 
TABLE 2

Sstr2 Binding in Different Tumors

\begin{tabular}{lcccc}
\hline \multicolumn{1}{c}{ Tumor } & Samples $(n)$ & $\begin{array}{c}\text { Antagonist }{ }^{125} \text { I-JR11 } \\
\text { binding }(\mathrm{dpm} / \mathrm{mg})^{*}\end{array}$ & $\begin{array}{c}\text { Agonist }{ }^{125} \text { I-Tyr }{ }^{3} \text {-octreotide } \\
\text { binding (dpm/mg) }\end{array}$ & $\begin{array}{c}\text { Antagonist-to-agonist } \\
\text { ratio }\end{array}$ \\
\hline Non-Hodgkin lymphoma & 15 & $3,005 \pm 499$ & $214 \pm 63$ & 14.0 \\
\hline Breast cancer & 13 & $4,105 \pm 1,092$ & $519 \pm 156$ & 7.9 \\
Renal cell carcinoma & 12 & $3,777 \pm 582$ & $348 \pm 49$ & 10.9 \\
\hline Pheochromocytoma & 5 & $7,852 \pm 876$ & $446 \pm 280$ & 17.6 \\
Medullary thyroid cancer & 5 & $2,173 \pm 555$ & $100 \pm 100$ & 21.8 \\
\hline leal NET & 4 & $8,470 \pm 944$ & $2,258 \pm 905$ & 3.8 \\
Small cell lung cancer & 4 & $7,759 \pm 1,294$ & $1,722 \pm 718$ & 4.5 \\
\hline Paraganglioma & 2 & $10,000 \pm 0$ & $641 \pm 169$ & 15.6 \\
\end{tabular}

${ }^{*}$ Data are mean \pm SEM.

Data are from Reubi et al. (20).

the sstr2 antagonist remained on the surface of the cells, ${ }^{177} \mathrm{Lu}$ DOTA-JR11 showed higher uptake and caused at least $60 \%$ more DNA double-strand breaks than ${ }^{177} \mathrm{Lu}$-DOTATATE, for which the internalization rate was high $(74 \% \pm 3 \%)(17)$.

In addition to ${ }^{177} \mathrm{Lu}-\mathrm{DOTA}-J R 11$, Nicolas et al. investigated ${ }^{90} \mathrm{Y}-$ and ${ }^{111}$ In-DOTA-JR11 as potential therapeutic alternatives (18). ${ }^{90}$ Y-DOTA-JR11 showed an approximately $20 \%$ lower tumor-to-kidney uptake ratio than ${ }^{177} \mathrm{Lu}$-DOTA-JR11 while having an approximately 5 times higher effective dose, both of which negatively affected its therapeutic index in comparison to the ${ }^{177} \mathrm{Lu}$-labeled compound. Nicolas et al. also showed that ${ }^{111} \mathrm{In}-$ DOTA-JR11 cannot be used as a surrogate of ${ }^{90}$ Y-DOTA-JR11 because of differences in their pharmacokinetics and affinity for sstr2 (18). Whether Auger electron emitters in combination with antagonists can be applied to PRRT remains unclear, but ${ }^{111} \mathrm{In}$ DOTA-JR11 exhibits excellent properties as an imaging agent.

\section{Novel Indications for Tumor Targeting with Radiolabeled sstr Antagonists}

The better performance of radiolabeled sstr antagonists than of agonists was also impressively demonstrated with human tumor specimens (20). About 60 human tissue samples from different tumors were analyzed by in vitro receptor autoradiography to compare the binding capacities of ${ }^{125}$ I-JR11 (sstr2 antagonist) and ${ }^{125} \mathrm{I}^{-\mathrm{Tyr}^{3}}{ }^{3}$-octreotide (sstr2 agonist) in successive tissue sections. The sstr2-binding affinities $\left(\mathrm{IC}_{50} \mathrm{~s}\right)$ of both ${ }^{125} \mathrm{I}$-labeled tracers were similar (20). Both radioligands efficiently bound to sstr2 in different tumor tissues. However, in all cases, the radiolabeled antagonist ${ }^{125} \mathrm{I}-\mathrm{JR} 11$ bound to more sstr2 sites in different tumors-with uptake from 3.8 to 21.8 times higher-than the agonist ${ }^{125} \mathrm{I}_{-} \mathrm{Tyr}^{3}$-octreotide (Table 2). Such significantly increased binding may not only increase the localization accuracy for tumors and metastases but also increase the efficacy of therapeutic interventions with radiolabeled sstr antagonists. Of particular interest is the fact that tumors other than gastroenteropancreatic NETs and lung NETs become targets for sstr2 antagonists despite low sstr2 densities; these tumors include breast cancer, small cell lung cancer, renal cell cancer, non-Hodgkin lymphomas, pheochromocytomas, and medullary thyroid cancer (Table 2). These tumors are not among those currently being routinely investigated with sstr imaging.
These in vitro human tumor data, together with the in vivo animal tumor data, are strong arguments that radiolabeled antagonists should be clinically tested in a wide range of tumors, including those other than NETs. Radiolabeled sstr2 antagonists should be useful not only for tumor imaging but also for targeted radionuclide therapy (theranostic approach).

\section{CLINICAL DEVELOPMENT OF RADIOLABELED SSTR ANTAGONISTS}

\section{Initial Human Studies with Diagnostic sstr Antagonists}

There is preclinical evidence that the higher tumor uptake and better tumor-to-background contrast of radiolabeled sstr2 antagonists than of agonists (15) may improve the image quality and detection rate of sstr SPECT and PET. A pilot study in 5 patients with NETs or thyroid cancer provided the first evidence that sstr imaging with the sstr2 antagonist ${ }^{111}$ In-DOTA-BASS was more effective than that with the U.S. Food and Drug Administration-approved radiotracer ${ }^{111}$ InDTPA-octreotide (OctreoScan; Mallinckrodt); the main advantages of the radiolabeled sstr2 antagonist were higher tumor uptake (4-fold), higher tumor-to-liver background ratios ( $\sim 2$-fold), and a greater number of detectable lesions (25/28 lesions vs. 17/28 lesions) (7). Figure 2 shows ${ }^{111}$ In-DTPA-octreotide, ${ }^{111}$ In-DOTA-BASS, and

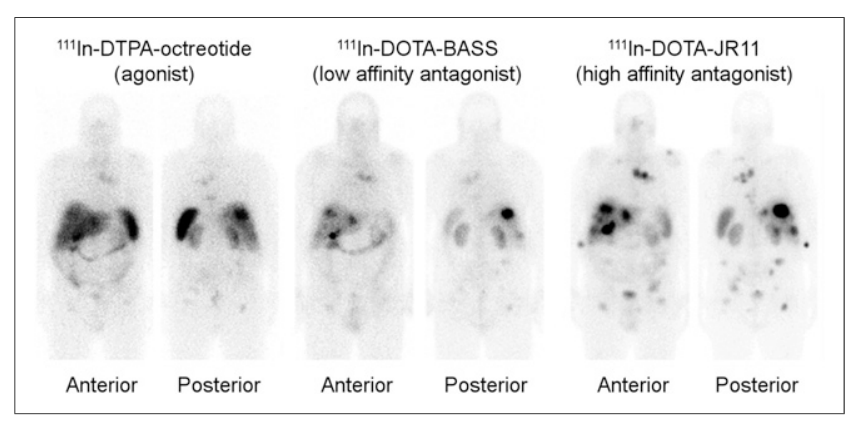

FIGURE 2. Comparison of ${ }^{111}$ In-DTPA-octreotide, ${ }^{111} \mathrm{In}$-DOTA-BASS, and ${ }^{111} \mathrm{In}$-DOTA-JR11 scintigraphy $24 \mathrm{~h}$ after administration of radiotracer in same patient with metastatic NET of unknown origin (grade G2). High-affinity sstr2 antagonist ${ }^{111}$ In-DOTA-JR11 showed higher tumor uptake and detected many more metastases than sstr agonist ${ }^{111} \mathrm{In}$-DTPA-octreotide and sst2 antagonist ${ }^{111}$ In-DOTA-BASS. 


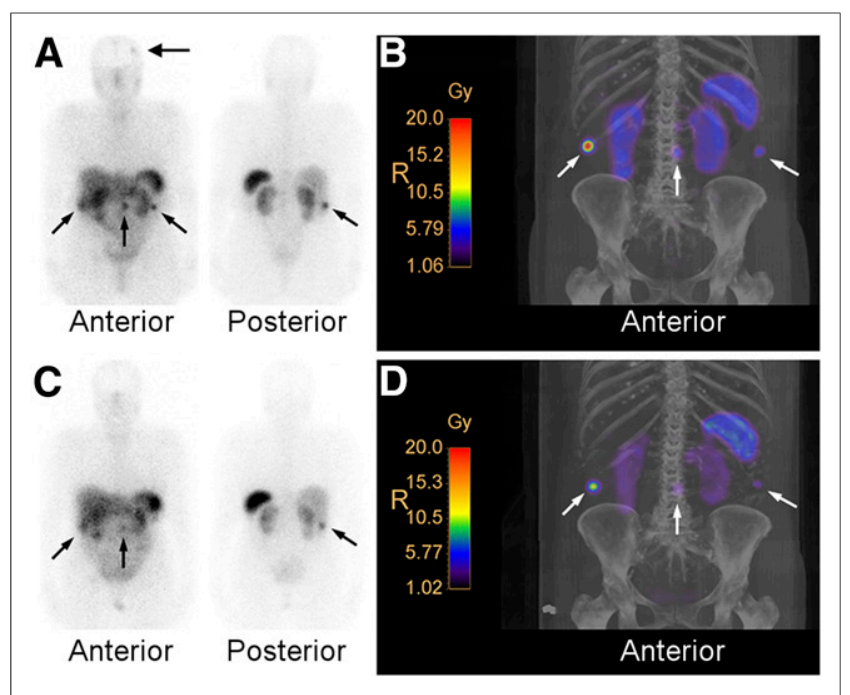

FIGURE 3. Comparison of ${ }^{177} \mathrm{Lu}$-DOTA-JR11 (A and B) and ${ }^{177} \mathrm{Lu}-$ DOTATATE (C and $D)$ in same patient with metastatic NET of ileum (grade G2). Planar scintigraphy $24 \mathrm{~h}$ after injection of $1,086 \mathrm{MBq}$ of ${ }^{177}$ Lu-DOTA-JR11 (A) and corresponding maximum-intensity-projection (MIP) image of isodose curves (B). Planar scintigraphy $24 \mathrm{~h}$ after injection of $994 \mathrm{MBq}$ of ${ }^{177} \mathrm{Lu}$-DOTATATE (C) and corresponding MIP image of isodose curves (D). Interval for injections was $3 \mathrm{wk}$. Large black arrow in A shows possible meningioma. Small black and white arrows show tumor lesions. Three-dimensional voxel dosimetry analysis revealed tumor doses of 4.2-20 Gy/GBq for ${ }^{177}$ Lu-DOTA-JR11 and 1.5-8.5 Gy/ GBq for ${ }^{177}$ Lu-DOTATATE (see scales in B and D).

another sstr2 antagonist ( ${ }^{111}$ In-DOTA-JR11) with improved sstr2 affinities in the same patient. The affinity profiles of all 3 radiotracers are shown in Table 1.

On the basis of affinity studies and preclinical results, the sstr2 antagonist ${ }^{68} \mathrm{Ga}-$ NODAGA-JR11 (Table 1) was selected for further clinical PET development. A phase 1/2 study comparing, in the same patients, PET/CT with 2 microdoses of ${ }^{68} \mathrm{Ga}$-NODAGAJR11 $\left({ }^{68} \mathrm{Ga}\right.$-OPS202) and PET/CT with ${ }^{68} \mathrm{Ga}$-DOTATOC was recently conducted (ClinicalTrials.gov identifier: NCT02162446). That study indicated increased image contrast for both doses of ${ }^{68} \mathrm{Ga}$-NODAGA-JR11 because of lower hepatic, intestinal, and pancreatic uptake, which, in turn, resulted in sensitivity and diagnostic accuracy higher than that of ${ }^{68} \mathrm{Ga}$-DOTATOC PET/CT for staging well-differentiated to moderately differentiated gastroenteropancreatic NETs (21). A "theranostic pair"- ${ }^{68} \mathrm{Ga}$-DOTAJR11 and ${ }^{177}$ Lu-DOTA-JR11 (Table 1) -was also investigated in NET patients in a single-center study (ClinicalTrials.gov identifier: NCT02609737).

\section{Initial Human Studies with Therapeutic sstr Antagonists}

There is preclinical evidence that radiolabeled sstr2 antagonists generate higher tumor doses and larger numbers of DNA doublestrand breaks than agonists, resulting in better treatment efficacy $(17,18)$. Indeed, sstr2 antagonist ${ }^{177} \mathrm{Lu}-\mathrm{DOTA}-J R 11$ was more effective than sstr2 agonist ${ }^{177}$ Lu-DOTATATE in a first-in-human study with 4 patients who had metastasized neuroendocrine neoplasias (grades G1-G3); the most relevant findings of that study were higher tumor doses (3.5-fold) (because of longer residence time and higher tumor uptake), higher tumor-to-kidney dose ratios ( $>2$-fold), tumor doses of up to 487 Gy after treatment with 3 cycles (total, 15.2 GBq) of ${ }^{177} \mathrm{Lu}-\mathrm{DOTA}-J R 11$, and high metabolic stability of ${ }^{177}$ Lu-DOTA-JR11 (because no metabolites were found in the urine) (22). Figure 3 shows a comparison of ${ }^{177} \mathrm{Lu}-$ DOTA-JR11 scintigraphy and ${ }^{177}$ Lu-DOTATATE scintigraphy as well as 3-dimensional voxel dosimetry analysis in patient 4 of that study. ${ }^{177} \mathrm{Lu}$-DOTA-JR11 $\left({ }^{177} \mathrm{Lu}-\mathrm{OPS} 201\right)$ is currently being evaluated in a phase $1 / 2$ multicenter study (ClinicalTrials.gov identifier: NCT02592707) and in a theranostic study (ClinicalTrials.gov identifier: NCT02609737).

\section{FUTURE DEVELOPMENTS}

Further evaluation of the diagnostic-therapeutic pair ${ }^{68} \mathrm{Ga}-$ NODAGA-JR11- ${ }^{177}$ Lu-DOTA-JR11 is warranted in larger-scale multicenter clinical trials as a theranostic approach in patients with gastroenteropancreatic NETs and other NETs. Other tumors that should be evaluated further with sstr antagonists are breast cancer, small cell lung cancer, renal cell cancer, non-Hodgkin lymphomas, pheochromocytomas, medullary thyroid cancer, and other neoplasms with sstr2 expression, including tumors with low levels of sstr2 expression. Optimizing the antagonist peptide amount, hepatic intraarterial injection, and use of alternative radionuclides (such as $\alpha$-emitters and $\beta^{+}$-emitters) with longer half-lives may further improve sstr targeting with radiolabeled antagonists. Last, but not least, other receptor systems, such as the gastrin-releasing peptide receptor and cholecystokinin receptor subtype 2 , are alternative targets for radiolabeled antagonists.

\section{CONCLUSION}

Until recently, it was thought that internalization of the radiotracer was mandatory for sstr-mediated imaging and therapy. In 2006, Ginj et al. proposed that radiolabeled sstr antagonists may perform better than agonists despite the lack of internalization (6). Recent advantages described in this article provide evidence that radiolabeled sstr antagonists have the potential to improve imaging and therapy not only of NETs but also of tumors that have not yet been the focus of sstr targeting. There is now evidence for a shift from radiolabeled sstr agonists to antagonists.

\section{DISCLOSURE}

Damian Wild is a consultant for Ipsen Pharma SAS. No other potential conflict of interest relevant to this article was reported.

\section{REFERENCES}

1. Ambrosini V, Fani M, Fanti S, Forrer F, Maecke HR. Radiopeptide imaging and therapy in Europe. J Nucl Med. 2011;52(suppl 2):42S-55S

2. Baumann T, Rottenburger C, Nicolas G, Wild D. Gastroenteropancreatic neuroendocrine tumours (GEP-NET): imaging and staging. Best Pract Res Clin Endocrinol Metab. 2016;30:45-57.

3. Strosberg J, El-Haddad G, Wolin E, et al. Phase 3 trial of ${ }^{177} \mathrm{Lu}$-dotatate for midgut neuroendocrine tumors. N Engl J Med. 2017;376:125-135.

4. Strosberg J, Wolin E, Chasen B, et al. ${ }^{177} \mathrm{Lu}$-dotatate significantly improves progression-free survival in patients with midgut neuroendocrine tumours: results of the phase III NETTER-1 trial [abstract]. Eur J Cancer. 2015;51(suppl 3): S710.

5. Pavel M, O'Toole D, Costa F, et al. ENETS consensus guidelines update for the management of distant metastatic disease of intestinal, pancreatic, bronchial neuroendocrine neoplasms (NEN) and NEN of unknown primary site. Neuroendocrinology. 2016;103:172-185.

6. Ginj M, Zhang H, Waser B, et al. Radiolabeled somatostatin receptor antagonists are preferable to agonists for in vivo peptide receptor targeting of tumors. Proc Natl Acad Sci USA. 2006;103:16436-16441. 
7. Wild D, Fani M, Behe M, et al. First clinical evidence that imaging with somatostatin receptor antagonists is feasible. J Nucl Med. 2011;52:1412-1417.

8. Bass RT, Buckwalter BL, Patel BP, et al. Identification and characterization of novel somatostatin antagonists. Mol Pharmacol. 1996;50:709-715.

9. Hocart SJ, Jain R, Murphy WA, Taylor JE, Coy DH. Highly potent cyclic disulfide antagonists of somatostatin. J Med Chem. 1999;42:1863-1871.

10. Cescato R, Erchegyi J, Waser B, et al. Design and in vitro characterization of highly sst2-selective somatostatin antagonists suitable for radiotargeting. $\mathrm{J} \mathrm{Med}$ Chem. 2008;51:4030-4037.

11. Reubi JC, Schaer JC, Wenger S, et al. SST3-selective potent peptidic somatostatin receptor antagonists. Proc Natl Acad Sci USA. 2000;97:13973-13978.

12. Reubi JC, Schar JC, Waser B, et al. Affinity profiles for human somatostatin receptor subtypes SST1-SST5 of somatostatin radiotracers selected for scintigraphic and radiotherapeutic use. Eur J Nucl Med. 2000;27:273-282.

13. Wang X, Fani M, Schulz S, Rivier J, Reubi JC, Maecke HR. Comprehensive evaluation of a somatostatin-based radiolabelled antagonist for diagnostic imaging and radionuclide therapy. Eur J Nucl Med Mol Imaging. 2012;39:1876-1885.

14. Wadas TJ, Eiblmaier M, Zheleznyak A, et al. Preparation and biological evaluation of ${ }^{64} \mathrm{Cu}-\mathrm{CB}-\mathrm{TE} 2 \mathrm{~A}-\mathrm{sst} 2-\mathrm{ANT}$, a somatostatin antagonist for PET imaging of somatostatin receptor-positive tumors. J Nucl Med. 2008;49:1819-1827.

15. Fani M, Braun F, Waser B, et al. Unexpected sensitivity of $\mathrm{sst}_{2}$ antagonists to Nterminal radiometal modifications. J Nucl Med. 2012;53:1481-1489.

16. Fani M, Del Pozzo L, Abiraj K, et al. PET of somatostatin receptor-positive tumors using ${ }^{64} \mathrm{Cu}$ - and ${ }^{68} \mathrm{Ga}$-somatostatin antagonists: the chelate makes the difference. J Nucl Med. 2011;52:1110-1118.
17. Dalm SU, Nonnekens J, Doeswijk GN, et al. Comparison of the therapeutic response to treatment with a ${ }^{177} \mathrm{Lu}$-labeled somatostatin receptor agonist and antagonist in preclinical models. J Nucl Med. 2016;57:260-265.

18. Nicolas GP, Mansi R, McDougall L, et al. Biodistribution, pharmacokinetics and dosimetry of ${ }^{177} \mathrm{Lu}-,{ }^{90} \mathrm{Y}$ - and ${ }^{111}$ In-labeled somatostatin receptor antagonist OPS201 in comparison to the agonist ${ }^{177}$ Lu-DOTA-TATE: the mass effect. J Nucl Med. April 27, 2017 [Epub ahead of print].

19. Beykan S, Dam JS, Eberlein U, et al. ${ }^{177}$ Lu-OPS201 targeting somatostatin receptors: in vivo biodistribution and dosimetry in a pig model. EJNMMI Res. 2016;6:50.

20. Reubi JC, Waser B, Macke H, Rivier J. Highly increased ${ }^{125}$ I-JR11 antagonist binding in vitro reveals novel indications for sst $_{2}$ targeting in human cancers. J Nucl Med. 2017;58:300-306.

21. Nicolas G, Mansi R, Vomstein S, et al. Wider safety window with radiolabeled somatostatin receptor antagonists over agonists [abstract]. J Nucl Med. 2015;56 (suppl 3):335.

22. Wild D, Fani M, Fischer R, et al. Comparison of somatostatin receptor agonist and antagonist for peptide receptor radionuclide therapy: a pilot study. $\mathrm{J} \mathrm{Nucl}$ Med. 2014;55:1248-1252.

23. Schottelius M, Simecek J, Hoffmann F, Willibald M, Schwaiger M, Wester HJ. Twins in spirit: episode $\mathrm{I} \longrightarrow$ comparative preclinical evaluation of $\left[{ }^{68} \mathrm{Ga}\right]$ DOTATATE and $\left[{ }^{68} \mathrm{Ga}\right]$ HA-DOTATATE. EJNMMI Res. 2015;5:22.

24. Antunes P, Ginj M, Zhang H, et al. Are radiogallium-labelled DOTA-conjugated somatostatin analogues superior to those labelled with other radiometals? Eur $J$ Nucl Med Mol Imaging. 2007;34:982-993. 